\title{
Effect of Citric Acid and Storage Containers on the Keeping Quality of Refined Soybean Oil
}

\author{
Jacob Olalekan Arawande**, Eniayo Ayodeji Komolafe ${ }^{\mathrm{b}}$ and Ittennu Oluwabummi Shakpo ${ }^{\mathrm{b}}$ \\ ${ }^{a}$ Department of Science Laboratory Technology, Rufus Giwa Polytechnic, P.M.B. 1019, \\ Owo, Ondo State, Nigeria \\ ${ }^{\text {b}}$ Department of Food Science and Technology, Rufus Giwa Polytechnic, P.M.B. 1019, Owo, \\ Ondo State, Nigeria
}

(received February 6, 2010; revised August 31, 2010; accepted September 27, 2010)

\begin{abstract}
Free fatty acids (FFA), acid value (AV), peroxide value (PV) and iodine value (IV) of the soybean oil in tinned cans, transparent white glass and plastic bottles were monthly monitored for one year at room temperature. The results revealed that the oil stored in tin containers had the highest FFA and AV of $0.334 \pm 0.054 \%$ oleic acid and $0.653 \pm 0.104 \mathrm{mg} \mathrm{KOH} / \mathrm{g}$ oil, respectively, while that in plastic containers had the lowest value of $0.252 \pm 0.033 \%$ oleic acid and $0.495 \pm 0.064 \mathrm{mg} \mathrm{KOH} / \mathrm{g}$ oil for the FFA and AV. Addition of food grade citric acid (FGCA) at $0.2 \%$ level increased the keeping quality of refined soybean oil stored in glass and plastic bottles both with respect to hydrolytic stability of the oil. However, it reduced the peroxide value and slightly increased the iodine value of oil in all the containers. The additive (FGCA) led to a higher reduction in the oxidative rancidity of the oil stored in plastic bottles as compared to that stored in glass and tinned cans. There was significant difference at $\mathrm{P}<0.05$ in FFA and AV of oil stored in tin and glass containers as well as in PV and IV of the oil stored in all the containers. The additive enhanced the shelf life with respect to oxidative stability of the oil the most in plastic bottles and the least in tinned cans.
\end{abstract}

Keywords: soybean oil, containers, citric acid, free fatty acids, acid value, peroxide value, iodine value

\section{Introduction}

Soybean oil remains in high demand due to low cholesterol level making it safer for human consumption (Arawande, 2008). Crude soybean oil is produced from soybean seeds which are cracked, adjusted for moisture content, rolled into flakes and solvent-extracted with commercial hexane. The crude oil is further subjected to refining (Wikipedia, 2007) through degumming, neutralization, bleaching and deodorisation (Arawande and Abitogun, 2009a).

Refined soybean oil is the predominant vegetable oil used domestically in edible oil products (Erickson et al., 1980). Application of soybean oil falls into two main categories: edible fat products, meant for human consumption, and industrial fat products, used for technical purposes (ASA, 1996). The oil is unique among vegetable oils due to its high content of unsaturated fatty acids and remains in liquid form much below the room temperature. It contains potential natural antioxidants which are not removed during processing thereby preventing the oxidative rancidity which may occur in the lipids present in the oil (Haumman, 1994). It contains 7-8\% linolenic acid which can be reduced during processing. The high content of

*Author for correspondence; E-mail: joawande1@yahoo.com linolenic acid is responsible for the development of off-flavour and off-odour during degradation of the oil.

Nowadays, there is a drastic shift from the consumption of common red palm oil and other edible oils to refined soybean oil (Arawande, 2008). Vegetable oil merchants sometimes purchase the oil when it is cheap and store it in different containers, such as plastic bottles, glass bottles and tinned cans, and later sell it during off season when it becomes expensive, without taking into consideration the deterioration of oil quality.

One of the major problems confronting the producers, sellers and consumers of oil is associated with the deterioration of oil during storage where in the oil turns rancid owing to high content of unsaturated fatty acids. However, the use of antioxidants reduces deterioration during the storage (Arawande and Abitogun, 2009b).

Several studies have been conducted earlier and reported on soybean oil. Carlson and Scott (1991) and Erickson et al. (1980) reported processing and utilisation of soy oil, whereas Abitogun et al. (2009) studied effects of phosphoric acid on physicochemical parameters of soybean oil. Arawande (2008) investigated effects of storage containers on the shelf life of refined soybean oil. The use of soybean oil as insect repellent has been 
established (Barnard and Xue, 2004; Fradin and Day, 2002). Arawande and Amoo (2009) reported effects of light and dark storage conditions on some quality parameters of refined soybean oil. The use of citric acid as a potential antioxidant on crude palm kernel oil was reported by Arawande and Abitogun (2009a). However, little or no work has been done on the combined effects of both citric acid and storage containers on the shelf life of refined soybean oil. The aim of the present work was to investigate the effects of storage containers (tinned can, glass and plastic bottles) and $0.2 \%$ food grade citric acid on the hydrolytic and oxidative stability of refined soybean oil, stored over a period of twelve months.

\section{Materials and Methods}

Refined soybean oil was obtained from the deodouriser of the Vegetable Oil Division Plant (Refinery) of Jof Ideal Family Farms Limited, Owo, Ondo State, Nigeria.The oil was obtained before it was fortified with vitamin A. Two sets of three different containers (tinned can, transparent white glass bottle and plastic bottle) of equal capacity $(750 \mathrm{~mL}$ ) were obtained, washed and dried. Each of these containers was filled with $700 \mathrm{~mL}$ of refined soybean oil leaving $50 \mathrm{~mL}$ air space. Food grade citric acid $(0.2 \%)$ was added to the oil in a set of three different containers which were thoroughly shaken while the other set contained only the oil sample and citric acid was not added. Free fatty acid (FFA), acid value (AV), peroxide value (PV) and iodine value (IV) of the oil samples were monthly determined using standard methods (AOCS, 1989) over a period of twelve months.
Statistical analysis. The results obtained were subjected to one-way analysis of variance (one-way ANOVA) and the Duncan multiple range test (DMRT) was used to separate the means.

\section{Results and Discussion}

Table 1 shows mean values of free fatty acid (FFA), acid value (AV), peroxide value (PV) and iodine value (IV) of refined soybean oil stored with and without $0.2 \%$ food grade citric acid (FGCA) in different containers (tinned can, transparent white glass bottle and plastic bottle) over a period of twelve months. The results revealed that the FFA and AV of the oil in all the storage conditions were linearly correlated. Both the FFA and AV of the oil stored in plastic bottles were the lowest while that in the tin containers were the highest. FGCA $(0.2 \%)$ lowered the FFA and AV of refined soybean oil stored in all the containers except that in tin. There was significant difference at $\mathrm{P}<0.05$ in both FFA and AV of refined soybean oil stored in tin and glass containers. FFA and AV both are measures of hydrolytic rancidity of oils; the higher their values in any lipid, the higher the degree of hydrolytic rancidity (Ihekoronye and Nggody, 1985). The overall assessment showed that $0.2 \%$ FGCA reduced hydrolytic rancidity of refined soybean oil stored in plastic and glass containers but increased it in tin container. Incorporation of the additive at the specified concentration level enhanced the keeping quality with respect to hydrolytic stability of the oil stored in plastic and glass bottles.

The PV of refined soybean oil stored for twelve months was the highest in tin and the lowest in plastic bottles. It was significantly different at $\mathrm{P}<0.05$ in all the storage

Table 1. Mean values of quality properties of refined soybean oil stored in different storage conditions for twelve months

\begin{tabular}{lllll}
\hline \hline Storage condition & $\begin{array}{l}\text { *Free fatty acid } \\
(\text { FFA }) \\
(\% \text { oleic acid) }\end{array}$ & $\begin{array}{l}\text { *Acid value } \\
(\mathrm{AV}) \\
(\mathrm{mg} \mathrm{KOH} / \mathrm{g} \text { oil })\end{array}$ & $\begin{array}{l}\text { *Peroxide value } \\
(\mathrm{PV}) \\
\left(\mathrm{Meq} \mathrm{O}_{2} / \mathrm{kg} \text { oil }\right)\end{array}$ & $\begin{array}{l}\text { *Iodine value } \\
(\mathrm{IV}) \\
(\mathrm{g} / 100 \mathrm{~g} \text { oil })\end{array}$ \\
\hline Tin & $0.334 \pm 0.054^{\mathrm{d}}$ & $0.653 \pm 0.104^{\mathrm{d}}$ & $125.420 \pm 27.725^{\mathrm{f}}$ & $137.675 \pm 1.195^{\mathrm{a}}$ \\
Tin $+0.2 \% \mathrm{CA}$ & $0.352 \pm 0.059^{\mathrm{e}}$ & $0.676 \pm 0.117^{\mathrm{e}}$ & $108.380 \pm 23.729^{\mathrm{e}}$ & $138.355 \pm 0.953^{\text {ab }}$ \\
Glass & $0.308 \pm 0.046^{\mathrm{c}}$ & $0.614 \pm 0.094^{\mathrm{c}}$ & $87.241 \pm 19.110^{\mathrm{d}}$ & $139.220 \pm 0.767^{\mathrm{b}}$ \\
Glass $+0.2 \% \mathrm{CA}$ & $0.286 \pm 0.077^{\mathrm{b}}$ & $0.560 \pm 0.154^{\mathrm{b}}$ & $46.614 \pm 9.072^{\mathrm{b}}$ & $140.725 \pm 0.376^{\mathrm{bc}}$ \\
Plastic & $0.252 \pm 0.033^{\mathrm{a}}$ & $0.495 \pm 0.064^{\mathrm{a}}$ & $53.586 \pm 10.120^{\mathrm{c}}$ & $140.550 \pm 0.412^{\mathrm{c}}$ \\
Plastic+ 0.2\%CA & $0.244 \pm 0.033^{\mathrm{a}}$ & $0.479 \pm 0.064^{\mathrm{a}}$ & $37.132 \pm 6.942^{\mathrm{a}}$ & $141.125 \pm 0.288^{\mathrm{d}}$ \\
\hline \hline
\end{tabular}

Within each column, mean values followed by the same superscript are significantly different at $\mathrm{P}<0.05$ level according to Duncan Multiple Range Test (DMRT); * = mean value of quality properties \pm standard error; CA= citric acid. 
conditions. 0.2\% FGCA lowered the PV of oil in all the containers. PV of the oil samples containing $0.2 \%$ FGCA was the least in plastic containers followed by glass containers and the highest in tin containers. The IV of refined soybean oil stored for twelve months was the highest in plastic bottles and the lowest in tin containers. IV of the oil was significantly different at $\mathrm{P}<0.05$ in all the containers. Oil samples containing $0.2 \%$ FGCA had slightly higher IV in all the containers. The values obtained for both PV and IV under the same storage conditions indicated that the two parameters (PV and IV) were indirectly correlated. The storage condition that had the highest IV gave the least PV and vice versa. Increase in iodine value (IV) is always accompanied with decrease in peroxide value (PV) owing to more $\mathrm{C}=\mathrm{C}$ unsaturated double bonds that are present in the lipid which are left to be oxidised, therefore, leaving more $\mathrm{C}=\mathrm{C}$ unsaturated double bond in the lipids for iodination reaction during iodine value determination (Arawande and Ademulegun, 2009). Goli et al. (2005) and Rossel (1994) reported that PV and IV were measures of oxidative stability of lipids and that the lower the value of PV of any lipid, the more the lipid is oxidatively stable. $0.2 \%$ FGCA inhibited oxidative rancidity of refined soybean oil in all the containers and thereby enhanced the keeping quality of oil, which was the most oxidatively stable in plastic bottles, followed by glass bottles and the least in tin containers.

Figures 1 and 2 show free fatty acid (FFA) and acid value (AV), respectively, of refined soybean oil stored with and without $0.2 \%$ FGCA in tin, glass and plastic containers for a period of twelve months. The plots of these parameters show a consistent trend. Considering

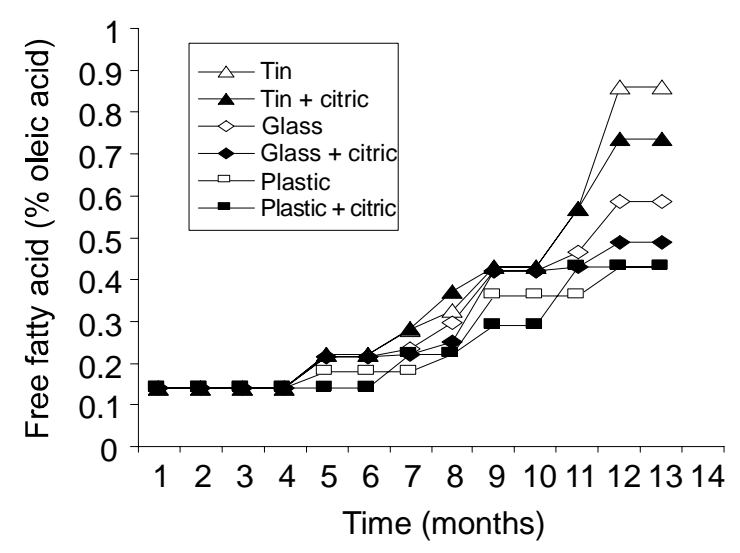

Fig. 1. Free fatty acid or refined soybean oil stored in different conditions for twelve months.

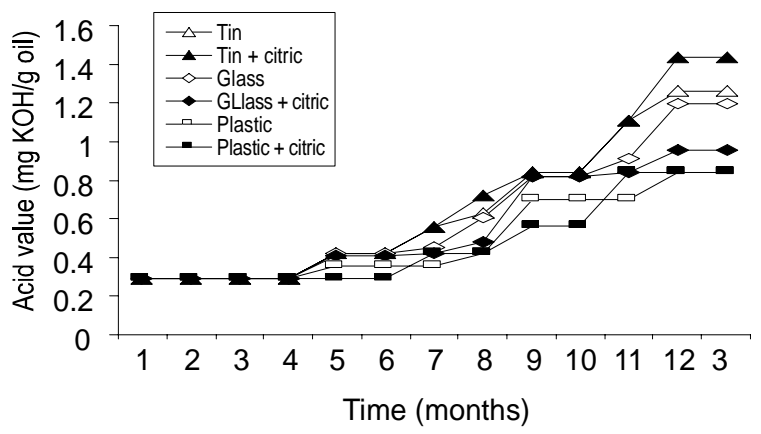

Fig. 2. Acid value of refined soybean oil stored in different conditions for twelve months.

the first six months of storage, it was observed that the oil stored in plastic bottles had the longest induction period while during the last three months of storage, refined soybean oil stored in tin containers had the highest value of FFA and AV, followed by the oil stored in glass bottles and the least in plastic bottles. In all the containers, the FFA and AV of refined soybean oil stored with $0.2 \%$ FGCA had lower values than those not containing additive. From the plots, it is obvious that the hydrolytic stabilitiy of refined soybean oil increased in the order; plastic + citric $>$ plastic $>$ glass + citric $>$ glass $>$ tin + citric $>$ tin .

Figures 3 and 4 depict peroxide value (PV) and iodine value (IV), respectively, of refined soybean oil stored with and without $0.2 \%$ FGCA in tin, glass and plastic containers for a period of twelve months. It was observed that as the PV of the oil increased, there was a slight decrease in the IV of the oil in all the storage conditions. This was due to reduction in the $\mathrm{C}=\mathrm{C}$ unsaturated double bonds in the hydrocarbon chain of the oil structure with

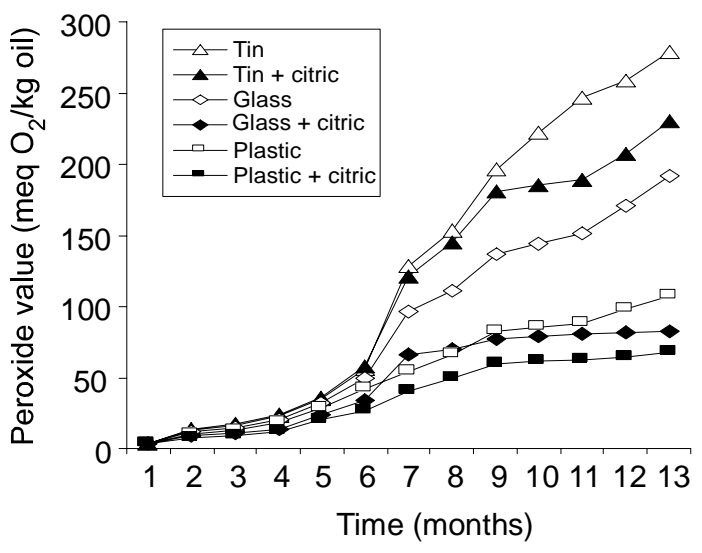

Fig. 3. Peroxide value of refined soybean oil stored in different conditions for twelve months. 


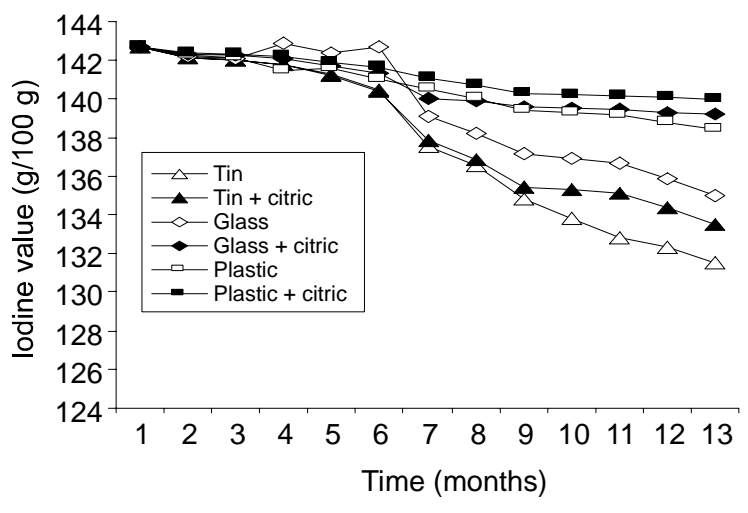

Fig. 4. Iodine value of refined soybean oil stored in different conditions for twelve months.

the increase in the oxidation processes thereby reducing the $\mathrm{C}=\mathrm{C}$ unsaturated double bond sites for iodine reaction (iodination) (Arawande and Amoo, 2009). In the first four months of storage, there was no sharp noticeable increase in the values of PV and IV of the oil in all the containers. Beyond this point, there were sudden incremental changes in the PV of the oil as the storage period increased while there was slight sudden decrease in the IV of the oil as the storage period increased. During the last five months of storage, addition of $0.2 \%$ FGCA to the oil remarkably reduced the PV of the oil in all the storage conditions, consequently resulting in a sharp increase in IV of the oil. PV of oil is the measure of oxidative stability of the oil which means that the lower is the value, the less is the oxidative rancidity of the oil. Therefore, the oxidative rancidity of refined soybean oil decreased in the order of storage conditions: plastic + citric $<$ glass + citric $<$ plastic $<$ glass $<$ tin + citric $<$ tin during the last five months of storage.

\section{Conclusion}

Storage conditions (such as containers and citric acid additive) of refined soybean oil affected the keeping quality of oil in varying degrees. Food grade citric acid $0.2 \%$ was an effective antioxidant against hydrolytic and oxidative rancidity of the refined soybean oil in all the containers under study. Refined soybean oil stored in plastic bottles was the least prone while those stored in tin containers were the most prone to both the hydrolytic and the oxidative rancidity. However, further research work is required on the soybean oil as well as on some other edible oils using varying concentrations of citric acid with different packaging materials for a longer period of time.

\section{References}

Abitogun, A.S., Jide, A.O., Arawande, J.O., Alademeyin, O.J., Omosheyin, A.C. 2009. Effects of phosphoric acid on the physicochemical parameters of soybean oil. The Internet Journal of Nutrition and Wellness, 8: (2).

AOCS 1989. Method cd 8:53. Official and Tentative Method of the American Oil Chemists Society, $4^{\text {th }}$ edition, American Oil Chemists Society, Champaign, Illinois, USA.

Arawande, J.O., Abitogun, A.S. 2009a. Antioxidative effects of citric acid on storage stability of refined soybean oil. In: Proceeding of the $33^{\text {rd }}$ Annual Conference/General Meeting on Food Processing in the Semi-Arid Regions: Challenges and Opportunities, pp. 317-318, Nigerian Institute of Food Science and Technology (NIFs), Nigeria.

Arawande, J.O., Abitogun, A.S. 2009b. Comparative studies on antioxidative potential of citric acid and methanolic extract of cabbage star leaf on crude palm kernel oil. Journal of Chemical Society of Nigeria, 34: 54-57.

Arawande, J.O., Ademulegun, T.I. 2009. Effects of light and dark conditions on some quality parameters of refined palm kernel oil stored in different containers. Journal of Science, Food and Hospitality, 1: 18-22.

Arawande, J.O., Amoo, I.A. 2009. Stability studies on refined soybean oil stored in various conditions. Pakistan Journal of Scientific and Industrial Research, 52: 303-306.

Arawande, J.O. 2008. Effect of storage containers on the shelf life of refined soybean oil. International Journal of Pure and Applied Sciences, 1: 76-81.

ASA 1996. American Soybean Association, http://www. oilseeds.org/asa.

Barnard, D.R., Xue, R.D. 2004. Laboratory evaluation of mosquito repellents against Aedes albopictus, Culex nigripalpus and Ochlerotatus triseriatus (Diptera: Culicidae). Journal of Medical Entomology, 41: 726-730.

Carlson, K.F., Scott, J.D. 1991. Recent developments and trends: Processing of oilseeds, fats and oils. Inform, 2: 1034-1060.

Erickson, D.R. Pryde, E.H., Brekke, O.L., Mounts, T.L., Falb, R.A. 1980. Handbook of Soy Oil Processing and Utilization, American Soybean Association and the American Oil Chemists Society, St. Louis, Missouri and Champaign, Illinois, USA. 
Fradin, M.S., Day, J.F. 2002. Comparative efficacy of insect repellents against mosquito bites. The New England Journal of Medicine, 347: 13-18.

Goli, A.H., Barzegar, M., Sahari, M.A. 2005. Antioxidant activity and total phenolic compound of pistachio (Pistachio vera) hull extracts. Food Chemistry, 92: 521- 525.

Haumman, B.F. 1994. Tools: hydrogenation, interesterification. Inform, 5: 668-667.
Ihekoronye, A.I., Ngoddy, P.O. 1985. Integrated Food Science and Technology for the Tropics, Macmillan Publisher Ltd, London, UK.

Rossel, J.B. 1994. Measurement of rancidity, In: Rancidity in Food, $3^{\text {rd }}$ edition, J.C. Allen and R.J. Hamilton (eds), pp. 22 -53, Blackie Academic, UK. Wikipedia, 2007. Soybeanoil. Wikipedia, the Free Encyclopedia. http//en.wikipedia.org/wiki/soybean oil.retrieved on 24/7/2007. 